\title{
Collaborating with communities: co-production or co-assessment?
}

\author{
William J. Sutherland, Gorm Shackelford and David Christian Rose
}

Conservation and development projects typically involve collaboration with local communities. It has been suggested that these collaborations should include the co-production of knowledge (e.g. Pohl et al., 2010; Wyborn, 2015; Nel et al., 2016), in which local communities work with researchers to produce new knowledge. Co-production is, however, expensive and we suggest here that co-assessment of existing knowledge is more cost-effective. We suggest the following three stages of using knowledge: collation, co-assessment, and then (rarely) co-production. We agree that other ways of knowing-including local, experience-based, and indigenous knowledges, as well as incorporating local valueshave an important role in solving environmental problems (Collins \& Evans, 2007; Sutherland et al., 2014), but we question whether it is effective to generate new knowledge with individual communities.

Co-production of knowledge has led to successful conservation outcomes (e.g. Nel et al., 2016). Beier et al. (2017) published a useful set of recommendations for effective co-production, building on previous suggestions for good knowledge exchange. However, there has been little critical evaluation of participatory science to determine whether the claimed benefits are actually achieved (Trimble \& Lázaro, 2014). Considering that co-production can be 'expensive, time-consuming, difficult, [and] ambitious' (Beier et al., 2017, p. 295), we argue that using coproduction of knowledge as the standard approach may be misplaced.

A commonly used argument in support of co-production is that local conditions vary markedly between sites, such that global knowledge has little or no local validity-it is the 'view from nowhere' (Shapin, 1998). Although research in ecology and conservation is often generalizable (Roughgarden et al., 1994), local conditions and outcomes do vary between locations. Therefore, it is necessary to interpret global knowledge and to consider its local validity, but this step is likely to be more efficient than simply deciding to ignore all pre-existing knowledge and co-produce new knowledge.

If knowledge is not generalizable then the costs of coproducing knowledge will have to be justified by its utility

William J. Sutherland, Gorm Shackelford \& David Christian Rose* Department of Zoology, University of Cambridge, Cambridge, UK

E-mailw.sutherland@zoo.cam.ac.uk

*Also at : School of Environmental Sciences, University of East Anglia, Norwich, UK to only the local community. This will rarely be a good investment. A back of the envelope calculation of the number of possible interventions that could be locally tested (at least a dozen?), times the number of communities (thousands in a country?), times the cost of co-producing a test (tens of thousands of dollars?) illustrates the problem. Surely we should plan generalizable experiments.

The model of co-assessment that we recommend is that external participants (e.g. practitioners) should approach a specific environmental problem, perhaps in a community, with knowledge of, and access to, collated global knowledge. Our suggestion is that the evidence should be collated globally, such that practitioners have access (as is being done for conservation by Sutherland et al., 2017). Co-assessment encourages scientists to collaborate with the local community by first assessing the validity of external knowledge, verifying how it relates to the local circumstances, before taking the decision to conduct costly local experiments (which may no longer be required if existing knowledge is adequate).

Figure 1 shows the essential elements of collaboration between conservationists and communities. Firstly, on the left is collation, which is the work of the global research community, who identify global challenges and potential solutions, collate the published evidence for the effectiveness of these solutions, and assess their effectiveness (Sutherland et al., 2004). Secondly, in the centre is co-assessment, which is a collaboration between researchers and local stakeholders, who assess the relevance of the global evidence to local conditions, collate additional local knowledge and experience, and assess this combination of global and local evidence to provide collective local guidance. Thirdly, on the right is co-production, which could involve collective learning, through adaptive management, or, in exceptional circumstances, new experiments that generate new, co-produced evidence. The results of the co-produced evidence could then be published, and would thereby become a part of the global evidence, to be used in future co-assessments.

Collation and co-assessment are the most cost effective stages. The question is: if these stages fail to provide the answer, when is co-production also appropriate? Since coproduction is time consuming and expensive, a critical issue is whether it will contribute to global knowledge or whether it just answers the specific local question. There seem likely to be few conservation issues for which the gain in local knowledge in one location will justify an extensive programme of co-production. 


\section{Global collation, co-assessment, co-production}

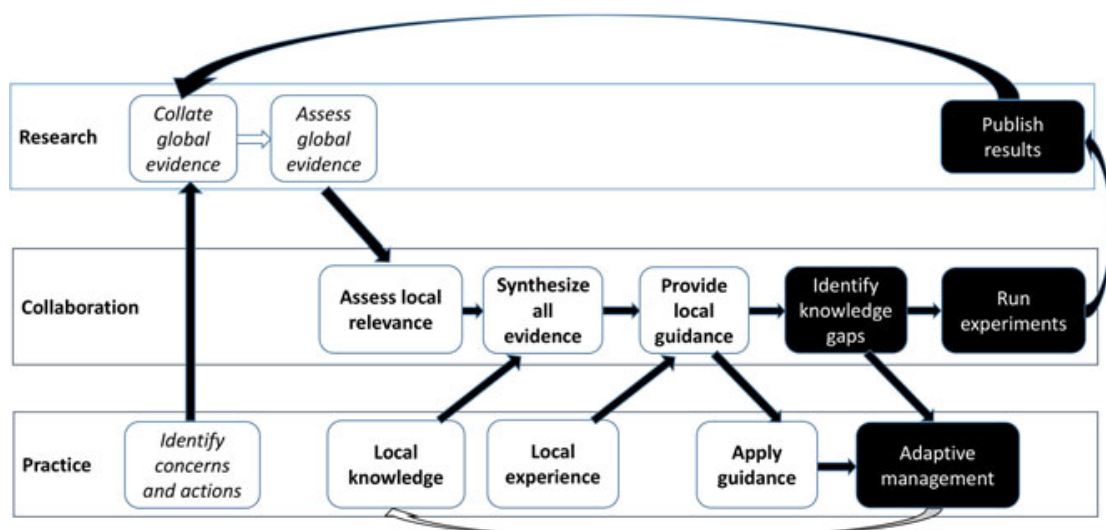

FIG. 1 Three stages of using knowledge to solve problems: $(1$, italics $)$ global collation of knowledge to determine level of relevant pre-existing knowledge; (2, bold) co-assessment of the existing global and local knowledge between researchers and stakeholders to identify local relevance as the basis of creating local plans; ( 3 , white text, black background) co-production of knowledge in which some testing is used as a process of adaptive management and, rarely, experiments are jointly carried out between practitioners and stakeholders to fill knowledge gaps and contribute to global knowledge.
Thus, we suggest that the research community should continue to develop the global collation of knowledge in conservation and development, simultaneously building a community that can work collaboratively to evaluate the quality and relevance of this knowledge under specific local conditions. More emphasis should also be placed on facilitating an efficient process for combining global knowledge with local knowledge, experiences, and values. Alongside the processes of collation and co-assessment, coproduction can be used to fill gaps in knowledge, and to test the effectiveness of interventions in places for which globally produced knowledge has less relevance but, critically, such co-produced knowledge is for global gains rather than for the single community.

\section{Acknowledgements}

WJS thanks Arcadia for funding.

\section{References}

Beier, P., Hansen, L.J., Helbrecht, L. \& Behar, D. (2017) A how-to guide for coproduction of actionable science. Conservation Letters, 10, 288-296.

Collins, H. \& Evans, R. (2007) Rethinking Expertise. University of Chicago Press, Chicago, USA.
Nel, J.L., Roux, D.J., Driver, A., Hill, L., Maherry, A.C. SNADDON, K. et al. (2016) Knowledge co-production and boundary work to promote implementation of conservation plans. Conservation Biology, 30, 176-188.

Pohl, C.S., Rist, S., Zimmermann, A., Fry, P., Gurung, G.S., SCHneider, F. et al. (2010) Researchers' roles in knowledge co-production: experience from sustainability research in Kenya, Switzerland, Bolivia and Nepal. Science and Public Policy, 37, 267-281.

Roughgarden, J., Pennington, T. \& Alexander, S. (1994) Dynamics of the rocky intertidal zone with remarks on generalization in ecology. Philosophical Transactions of the Royal Society B, 343, 79-85.

Shapin, S. (1998) Placing the view from nowhere: historical and sociological problems in the location of science, Transactions of the Institute of British Geographers, 23, 5-12.

Sutherland, W.J., Dicks, L.V., Ockendon, N. \& Smith, R.K. (2017) What Works in Conservation. Open Book Publishers, Cambridge, UK.

Sutherland, W.J., Gardner, T.A., Haider, L.J. \& Dicks, L.V. (2014) How can local and traditional knowledge be effectively incorporated into international assessments? Oryx, 48, 1-2.

Sutherland, W.J., Pullin, A.S., Dolman, P.M. \& Knight, T.M. (2004) The need for evidence-based conservation. Trends in Ecology and Evolution, 19, 305-308.

Trimble, M. \& LAzaro, M. (2014) Evaluation criteria for participatory research: insights from coastal Uruguay. Environmental Management, 54, 122-137.

W yвоRn, C.A. (2015) Connecting knowledge with action through coproductive capacities: adaptive governance and connectivity conservation. Ecology and Society, 20, 11, http://dx.doi.org/10.5751/ ES-06510-200111. 